\title{
Design and fabrication of wheel removing machine
}

\author{
A. Sivakumar ${ }^{1 *}$ P. Sathia Morthi ${ }^{2}$ A. Peer Mohamed Essac ${ }^{3}$ S. Mohana Prasath ${ }^{3}$ M. Mukundhan ${ }^{3}$ \\ Associate Professor, Department of Mechanical Engineering, Kongu Engineering College, \\ Erode, Tamil Nadu. ${ }^{*}$ \\ Professor, Department of Mechanical Engineering, Kongu Engineering College, Erode, \\ Tamil Nadu. ${ }^{2}$ \\ UG Students, Department of Mechanical Engineering, Kongu Engineering College, Erode, \\ Tamil Nadu. ${ }^{3}$ \\ E-mail:askmech@kongu.ac.in
}

\section{ABSTRACT}

The proposed system's basic premise is to reduce personnel during nut fitting and removing wheels from autos. The motor is at the heart of the project and its implementation. Motor, Nut fitting arrangement (multi nut remover), and spur gear arrangement are the components employed here for the efficient operation of separate blocks. The model's main goal is to remove all of a wheel's nuts at once, rather than one by one. The model's premise is to use a spur gear to transfer relative motion to other gears. The primary spur gear is connected to the motor shaft in the model, which rotates due to the motor. The primary gear is the driver, while the secondary gears are the driven. The major gear is located in the model's center. The secondary gears and the primary gear are in sync. To ensure precise meshing and tool spacing, the secondary gears are set at predetermined distances. The drive axle is equipped with primary gear. The cover has several auxiliary axles that extend through it. Each secondary axle has a first end that is positioned inside the housing and a second end that extends outwardly from the cover. One of the first ends is attached to each of several secondary gears. Each of the secondary gears is in contact with the primary gear. One of the secondary axles is connected to each of the couplers. The project and implementation must provide the motor with both positive and negative potential. If we press the corresponding switch for forwarding rotation, the nut will be fixed; if we press the corresponding switch for reverse rotation, the polarity will be reversed, and the nut will be removed. The motor can be controlled according to the needs of the operator. To tighten or remove the nut, the operator should lift the model and place it in the proper location.

\section{INTRODUCTION}

In human life, a vehicle is an important machine. Nowadays, every family owns at least one automobile to facilitate and speed up transportation. The tool set-up for an automobile is a T-nut wrench and an automobile jacker, which are difficult to use for a woman or a teen to open their car nut. Tire difficulties are one of a vehicle's issues. If the car tires develop a problem, the user must remove the tires and address the issue. It's also difficult to remove the tire's nut for a car user, especially for ladies. The challenges are time- wasting and the necessity for force. There is no easy-to-use tool for removing nuts. The time it takes to open a car tire nut is too long, and it wastes the time of the driver by requiring a lot of force, which is difficult for women. To avoid wasting time and exerting excessive power, a tool has been developed that can remove four-tire nuts in a single operation while reducing the force applied. 


\section{MAJOR COMPONENTS}

\section{MOTOR}

Any group of rotating electrical machines that transform direct current electrical energy into mechanical energy is known as a DC motor. The most common varieties rely on magnetic fields to produce forces. Almost all DC motors contain an internal mechanism, either electromechanical or electronic, that changes the direction of current flow in a portion of the motor regularly. The number of stator and armature fields, as well as how they are coupled, all influence the speed and torque regulation characteristics. The voltage provided to the armature can be changed to adjust the speed of a DC motor. Variable resistance was included in the armature circuit or field circuit, allowing for speed control. Power electronics systems are frequently used to regulate modern DC motors, which alter the voltage by "chopping" the DC into on and off cycles with a lower voltage.

\section{GEAR}

The simplest sort of gear is spur gears. A gear with involute teeth cut on a cylindrical surface, either straight or helically. To transmit power between parallel shafts, two similar gears are employed. They are made up of a cylinder or disc with teeth that protrude radially. The edge of each tooth is straight and oriented parallel to the axis of rotation, despite the teeth not being straight sided Only when these gears are mounted on parallel shafts do they mesh properly. Spur gears perform well at modest speeds but are loud at higher speeds.

\section{SHAFT}

A shaft is a revolving or stationary component with a circular cross-section in most cases. A shaft's primary function is to transfer torque from a driving to a driven device. If the shaft rotates, it is normally transferring power; if the shaft does not rotate, it is merely sending torque and is most likely opposing torque transfer.
Gears, links and are mechanical components that are directly placed on shafts. Bearings are used to support a shaft. Pins, splines, keys, clamping bushes, press fits, bonded joints, and occasionally welded connections are utilized to convey torque to the mounted components. These components can convey torque to and from the shaft, and they also affect the shaft's strength, therefore they must be considered while designing the shaft. Torque, direct shear loading, tensile loading, and compressive loading are all applied to shafts. The cumulative effect of all of these types of loads must be considered when designing a shaft. When shafts are rotating at critical speeds, they must be designed to account for increased torque when starting up, inertial loads, fatigue loading, and unstable loading .

\section{MULTI NUT REMOVER}

A multi nut remover is a tool designed to make replacing a vehicle's wheels easier and faster. Without the use of an electric motor or any hydraulic or pneumatic systems, many lug nuts can be removed at once. The planetary shafts are perfectly aligned with the lug nuts' pitch circle position. This method may be used to remove any number of lug nuts; however, the gear design differs depending on key characteristics such as the number of lug nuts and the diameter of the pitch circle.

\section{BATTERY}

7.30 Amp-Hour at 12 Volts Chrome Battery's Sealed Lead Acid (SLA) batteries with T1 Terminals are made of leadcalcium alloy with absorbed glass mat AGM technology, making them entirely maintenance-free and high-performing. High cell compression and fiberglass mat separators enhance battery life by providing excellent vibration resistance in the harshest conditions. Even when surge current isn't a concern, lead-acid batteries are extensively employed, even though alternate designs could yield higher energy. 


\section{DESIGN CALCULATION}

Speed of $12 \mathrm{v}$ DC motor $(\mathrm{N} 1)=80 \mathrm{rpm}$

Torque of $12 \mathrm{v}$ DC motor $(\mathrm{T} 1)=110 \mathrm{Nm}$

Torque required to remove wheel $=110$

$\mathrm{Nm}$ In pinion,

$$
\mathrm{P}=\frac{2 \pi N 1}{T 60}^{*}
$$

$$
P=\underline{2 \pi * 80} * 110
$$

60

In gear,

$$
\begin{gathered}
P=\frac{2 \pi N 2}{60} * T \\
P=\frac{2 \pi N 2}{60} * 110
\end{gathered}
$$

Equating 1 and

$$
2
$$

$$
\begin{gathered}
\frac{2 \pi * 80}{60} * 110=\underline{2 \pi N 2} * 110 \\
\quad 60 \\
N 2=80 \mathrm{rpm}
\end{gathered}
$$

Gear ratio $=\underline{N 2}$

$$
\begin{aligned}
& N 1 \\
= & \underline{80} \\
& 80 \\
= & 1: 1
\end{aligned}
$$

\section{DESIGN OF BALL BEARING}

Bearing No. 6202 (Databook pg.no 4.13)

Outer Diameter of Bearing (D) $=37 \mathrm{~mm}$

Thickness of Bearing (B) $\quad=12 \mathrm{~mm}$

Inner Diameter of the Bearing $(d)=15 \mathrm{~mm}$

$r_{l}=$ Corner radii on shaft and housing

$\mathrm{r}_{1}=1($ From design data book $)$

Maximum Speed =14,000 rpm
Mean Diameter $(\mathrm{dm})=(\mathrm{D}+\mathrm{d}) / 2$

$$
=\left(\begin{array}{c}
37+15) / \\
2
\end{array}\right.
$$

$$
\mathrm{dm}=26 \mathrm{~mm}
$$

\section{DESIGN}

Figures 1 and 2 given below shows the Design and Prototype of Wheel Removing Machin

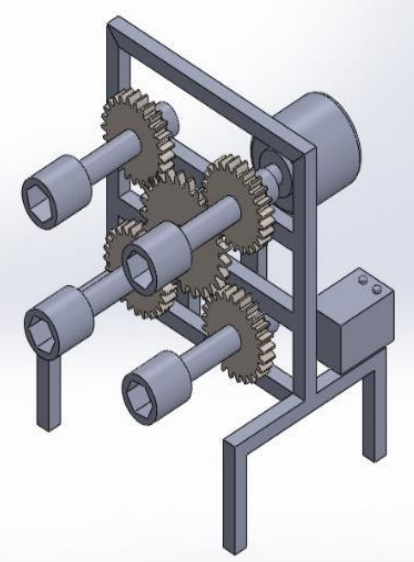

Fig.1. Design of Wheel Removing Machine 


\section{PROTOTYPE}

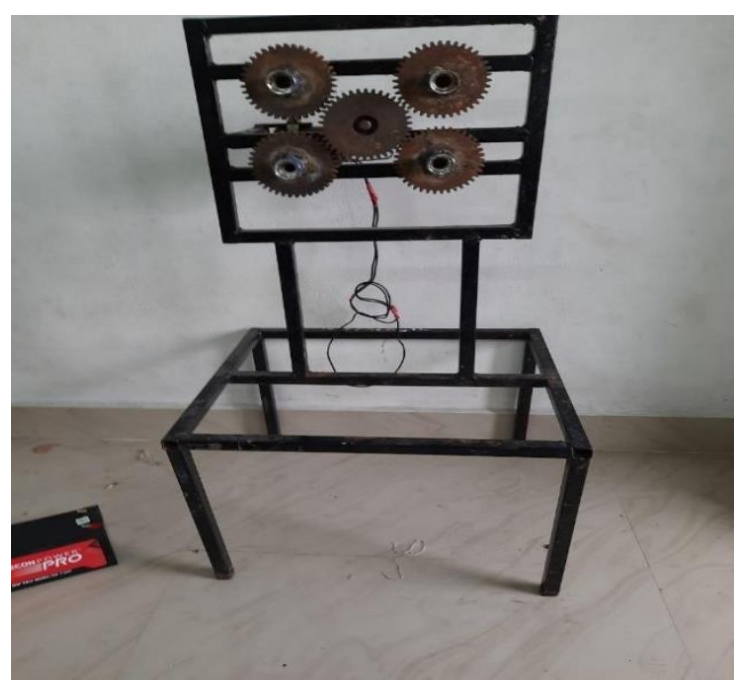

Fig.2. Prototype of Wheel Removing Machine

\section{CONCLUSION}

A multi-nut remover is a tool that can remove numerous nuts in one go. Because these are frequently used to remove wheel nuts, the mechanical effort required to remove the wheel is minimal. The Multi nut remover can be utilized in both production and vehicle units. The model's weight can be lowered by utilizing a lightweight material for the base plate. The multi-nut extractor makes removing the wheel nuts a breeze.

\section{REFERENCES}

Amol Bhanage, "Design and Modelling of 6 In 1 All - Nut Remover for Automobile Wheels": in International Advanced Research Journal in Science, (ICAME2016) March 2016.

Ananthu P, Design and Development of Multi-Nut Tightener 2020: IJCRT Volume 8, Issue 7 July 2020

Arif Khan, Design and Fabrication of Multi Nut Opener and Tightener "Mechanics of Machines": Tata McGraw-Hill, 2004.

Avinash S, Design and Fabrication of Multi Nut Removing Tool Volume: 3 Issue:11 November 2014

Jayesh Patel, IJSTE - International Journal of Science Technology \& Engineering: Volume 4 Issue 1 July 2 